\title{
Is Fractionated exhaled nitric oxide (FeNO) useful as a biomarker in eosinophilic esophagitis?
}

\author{
Alejandro Raúl Gratacós Gómez ${ }^{1}$, Juana Bautista Joyanes Romoํㅜ Jaime Vinicio Meneses \\ Sotomayor $^{1}$, Alberto Palacios Cañas ${ }^{1}$, Lucia Moreno Lozano ${ }^{1}$, and Elisa Gómez Torrijos ${ }^{1}$ \\ ${ }^{1}$ Hospital General Universitario de Ciudad Real
}

December 28, 2021

\begin{abstract}
FeNO levels are not useful either for diagnosis or for evaluating response to treatment. Although, subjects without asthma with FeNO-l [?] 30 ppb have probability to EoE,
\end{abstract}

\section{To Editor:}

\section{Títle:}

Is Fractionated exhaled nitric oxide (FeNO) useful as a biomarker in eosinophilic esophagitis?

Brief title : Is FeNO useful in eosinophilic esophagitis?

Conclusion that summarizes the letter:

FeNO levels are not useful either for diagnosis or for evaluating response to treatment. Although, subjects without asthma with FeNO-l [?] 30 ppb have probability to EoE,

\section{Main text}

Introduction

Eosinophilic esophagitis (EoE) is defined by esophageal dysfunction symptoms and [?] 15 eosinophils/highpowered field (eos/hpf), in the esophageal mucosa, after ruling out other causes of esophageal eosinophilia (1). Fractionated exhaled nitric oxide (FeNO) measures eosinophilic inflammation, therefore it is widely used in bronchial asthma (2). On the other hand, some research had been done on its usefulness in other diseases, especially atopic and/or extra-respiratory diseases.

Objectives. 1, Investigate whether FeNO levels (FeNO-l) are useful for diagnostic and for to evaluate response to therapy. 2, To study whether there are differences between EoE patients and control subjects (CS) (age, sex, FeNO levels, presence of asthma and rhinitis), and calculate the sensitivity and specificity of FeNO-l.

Methods

Prospective, descriptive, and analytical study in patients diagnosed of EoE, according to consensus guidelines (1).

Study variables: EoE, age, sex, asthma, rhinitis, and FeNO-l (before and after treatment) in patients and CS, sensitivity, specificity, positive predictive value, and negative predictive value of FeNO-l. We carried out the statistical study with IBM-SPSS software 
All patients have signed the informed consent. This study was approved by the Ethical Committee and follows the Principles of the Declaration of Helsinki

Results

We have studied FeNO-l in 204 patients, 71 had EoE. Average age 38 and FeNO-l, 19 ppb (median). Asthmatics 135 and rhinitis 121 .

There are significant differences between patients and CS in: age, sex, FeNO-l (higher in patients in general and non-asthmatic patients) and with FeNO-l [?]30 PPB in non-asthmatic patients. We have not found significant differences between FeNO-l before and after treatment (Tables 1 and 2).

Discussion

There is still no minimally invasive biomarker that has been incorporated into guidelines recommendations for routine clinical practice in the EoE (3). Since recent studies found elevated FeNO-l in multiples diseases (4). These observations suggest us a possible role for FeNO in extra-respiratory diseases with TH2 inflammation as EoE.

The increased levels of inducible nitric oxide (NO) synthetase in the esophageal mucosa of patients with EoE experiences upregulation during LTH2-mediated responses. An increased production of NO can be transmitted through the esophagus and mixed with the exhaled respiratory gases (5). This would explicate measurement of FeNO-l, to reflect eosinophilic inflammation that occurs in the esophagus

Has been evaluated whether gastroesophageal reflux disease (GERD) had an impact on the FeNO-l in patients without respiratory disease. The authors concluded that GERD did not significantly affect FeNO-l. Other study concluded that there is little influence of GERD on FeNO-l in asthmatics. We have not found studies on FeNO-l in EoE and SC (with/without asthma and/or rhinitis) to compare our results.

In other work, we have not found significant differences between FeNO-l in patients with EoE before treatment (active EoE) and after same (EoE in remission) (4). Therefore FeNO-l are not useful to evaluate the remission of EoE or the effectiveness of treatment. Besides, other study conclude FeNO-l likely has limited clinical utility for predicting severity of esophageal eosinophilia (5). Fortunately, several promising biomarkers are under study which may reduce the need for repeated endoscopic biopsies (3)

Our results regarding the sensitivity of FeNO-l are very similar to those of other authors (6). If we recode phenol-l, in non-asthmatic patients with levels [?] 30 have a high probability of suffering from EoE.

Small number of FeNO-l determinations in non-asthmatic EoE patients is a limitation of this study. But it has the strength it is a prospective study

In conclusion, although FeNO-l are elevated in patients with EoE, they are not useful either for diagnosis or for evaluating response to treatment. However, subjects without asthma with FeNO-l [?] 30 ppb have probability to EoE.

References

1. Dellon ES, Liacouras CA, Molina-Infante J, Furuta GT, Spergel JM, Zevit N, et al. Updated International Consensus Diagnostic Criteria for Eosinophilic Esophagitis: Proceedings of the AGREE Conference. Gastroenterology. 2018;155(4):1022-1033.

2. Ulrik CS, Lange P, Hilberg O. Fractional exhaled nitric oxide as a determinant for the clinical course of asthma: a systematic review. Eur Clin Respir J. 2021. 24;8(1):1891725.

3. Hines BT, Rank MA, Wright BL, Marks LA, Hagan JB, Straumann A, Greenhawt M, Dellon ES. Minimally invasive biomarker studies in eosinophilic esophagitis: A systematic review. Ann Allergy Asthma Immunol. 2018;121(2):218-228. 
4. Leung J, Nguyen-Traxler A, Lee EM, Yip JS, Weinstock JV, Chan WW, Ngo P, Weinstein BJ, Bonis PA. Assessment of fractionated exhaled nitric oxide as a biomarker for the treatment of eosinophilic esophagitis. Allergy Asthma Proc. 201; 33(6):519-24.

5. Johnson K, Iyer V, Katzka D, Ravi K, Lennon R, Pendegraft R, Geno D, Alexander J. Poor Relationship Between Fractionated Exhaled Nitric Oxide and Disease Activity in Eosinophilic Esophagitis. Dysphagia. 2019;34(1):138-144.

6. Lanz MJ, Guerrero RA, Gonzalez-Vallina R. Measurement of exhaled nitric oxide in the evaluation for eosinophilic esophagitis in children. Ann Allergy Asthma Immunol. 2012;109(1):81-2.

Key words: Esophagitis; eosinophils; asthma; rhinitis

Words number : 600

Funding information : This work has not been funded by anything, or by anyone

Acknowledgment : None

Conflict Interest : None of the authors of this work have a conflict of interest.

\section{Authors contribution}

Gratacos Gomez and Gomez Torrijos conceived the study and wrote the protocol, recruited the bibliography, and thoroughly reviewed the manuscript before submitting it.

Joyanes Romo and Palacios Canas were responsible for the recruitment and clinical evaluations of the patients.

Moreno Lozano was responsible for data analysis and statistical analysis.

Meneses Sotomayor wrote this manuscript and translated it into English, after it was reviewed and approved by all the authors.

\section{Author names and affiliations:}

Alejandro Raul Gratacos Gomez; e-mail:alexgr3297@gmail.com

Juana Bautista Joyanes Romo ; e-mail:jjoyanesromo@gmail.com

Jaime Vinicio Meneses Sotomayor ; e-mail:jmenesess@sescam.jccm.es

Alberto Palacios Canas ; e-mail: apcanas@sescam.jccm.es

Lucia Moreno Lozano ; lucimoreloza@gmail.com

Elisa Gomez Torrijos ; e-mail: egomezt.cr@gmail.com.

Allergy Section. Hospital General Universitario. C/ Obispo R. Torija s/n. Ciudad Real. CP 13005. Spain

\section{Corresponding autor:}

Elisa Gomez Torrijos

e-mail: egomezt.cr@gmail.com

Address: C/Obispo R. Torija s/n. 13005. Ciudad Real. SPAIN

Phone number: 0034926278000 Ext 79556

Table 1. Comparison of patients versus controls globally (1.1). Comparison of FeNO-levels between patients and control subjects, considering the presence or absence of asthma (1.2). Comparison of FeNO-levels between patients and control subjects, considering the presence presence or absence of rhinitis and asthma 
(1.3). Results of the recoding of FeNO [?] and $<30$ in patients and control subjects and Chi-square tests $(X$ 2) (1.4)

\begin{tabular}{|c|c|c|c|}
\hline Variables 1.1 & $\mathrm{EoE}$ & No EoE & $\mathrm{P}$ \\
\hline Patient: & $71(35 \%)$ & $169(65 \%)$ & \\
\hline Age (years) & M: $32(28.5)$ & 44. $5(32.25)$ & 0.031 \\
\hline Sex (Female) & $19 / 71(26.76 \%)$ & $82 / 133(61.36 \%)$ & $<0.001$ \\
\hline FeNO (ppb) & $26.5(28)$ & $16(24)$ & 0.001 \\
\hline Asthma & $44 / 71(61.97 \%)$ & $93 / 133(69.17 \%)$ & 0.299 \\
\hline Rhinitis & $42 / 71(59.15 \%)$ & $79 / 133(59.4 \%)$ & 0.855 \\
\hline \multicolumn{4}{|l|}{1.2} \\
\hline Non-asthmatic 69 & $27 / 71(38 \%)$ & $42 / 133(31.57 \%)$ & - \\
\hline FeNO ppb & $21.5(18)$ & $12(66)$ & $<0.001$ \\
\hline Asthmatic 135 & $44 / 71(62 \%)$ & $91 / 133(12.78 \%)$ & - \\
\hline FeNO (ppb) & $34.66(32)$ & $30(18)$ & 0.059 \\
\hline \multicolumn{4}{|l|}{1.3} \\
\hline \multicolumn{4}{|l|}{$\begin{array}{l}\text { Subjects with rhinitis } \\
\text { and without asthma }\end{array}$} \\
\hline $\begin{array}{l}\text { With rhinitis and } \\
\text { without asthma }\end{array}$ & $13 / 71(18.3 \%)$ & $17 / 133(12.78 \%)$ & - \\
\hline FeNO (ppb) & $21.84 \pm 2.68$ & $16.64 \pm 3.73$ & 0.02 \\
\hline \multicolumn{4}{|l|}{$\begin{array}{l}\text { Subjects without } \\
\text { rhinitis and without } \\
\text { asthma }\end{array}$} \\
\hline $\begin{array}{l}\text { Without rhinitis and } \\
\text { without asthma }\end{array}$ & $17 / 71(18.3 \%)$ & $25 / 133(18,79 \%)$ & - \\
\hline FeNO (ppb) & $30.3 \pm 5.7$ & $13.5 \pm 1.23$ & 0.013 \\
\hline \multicolumn{4}{|l|}{$\begin{array}{l}\text { Subjects without } \\
\text { rhinitis (With or } \\
\text { without asthma) }\end{array}$} \\
\hline $\begin{array}{l}\text { Without rhinitis (With } \\
\text { or without asthma) }\end{array}$ & $28 / 71(39.43 \%)$ & $55 / 133(412.35 \%)$ & - \\
\hline FeNO (ppb) & $34 \pm 4$ & $21.81 \pm 2.92$ & 0.001 \\
\hline 1.4 & & & \\
\hline $\begin{array}{l}\text { Recoding of } \mathrm{FeNO}<\text { and } \\
{[?] 30 \mathrm{PPB} \text { and } \mathrm{Chi}} \\
\text { square Test }\left(\mathrm{X}^{2}\right)\end{array}$ & & & 0.003 \\
\hline FeNO levels $<30 \mathrm{ppb}$ & $26(41.3 \%)$ & $37(58.7 \%)$ & \\
\hline FeNO levels [?]30 ppb & $12(85.7 \%) 2$ & $2(14.3 \%)$ & \\
\hline
\end{tabular}

Table 2. Descriptive statistics and p-values of different study variables comparing patients and controls (men and women) (2.1). Comparison of FeNO levels before and after treatment using the Wilcoxon rank test (2.2). Calculation of sensitivity, specificity, positive predictive value, and negative predictive value of FeNO-levels (2.3)

\begin{tabular}{llll}
\hline Variables 2.1 Men:103 & EoE & No EoE & P \\
\hline Age (Years) & $32.01 \pm 2.24$ & $33.92 \pm 3.05$ & 0.992 \\
Feno (ppb) & $33.09 \pm 3.44$ & $31.03 \pm 4.59$ & 0.60 \\
Asthma & $34 / 52(33.66 \%)$ & $38 / 51(37.62 \%)$ & 0.385 \\
Rhinitis & $31 / 52(60.78 \%)$ & $29 / 51(55,76 \%)$ & 0.606
\end{tabular}




\begin{tabular}{llll}
\hline Variables 2.1 Men:103 & EoE & No EoE & $\mathrm{P}$ \\
\hline Woman:101 & $38.4 \pm 4.1$ & $43.66 \pm 1.96$ & 0.147 \\
Age (years & $29.5 \pm 4.9$ & $25.92 \pm 3.3$ & 0.058 \\
Feno (Ppb) & $10 / 20(50 \%)$ & $53 / 81(65.43 \%)$ & 0.202 \\
Asthma & $11 / 20(55 \%)$ & $50 / 81(61.72 \%)$ & 0.805 \\
Rhinitis & Response & to treatment & 0.603 \\
2.2 Evaluation of & Median:29 & & \\
FeNo levels & Intercuartile range 17.25 & & \\
Pre-treartment & Median:25 Interquartile & & \\
FeNO levels & range: 20.75 & & Total \\
Post-treatment & & No Esophagitis & Positive predictive value \\
2.3 & Esophagitis & 95 patients & $95(36+95)=72.5 \%$ \\
Variable FeNO & Eosinophilic & 38 patients & Positive predictive value \\
FeNO <26.6 (28) ppb & 36 patients & & $35(35+38)=47.9 \%$ \\
FeNO [?]26.6 (28) ppb & 35 patients & 133 & 204 \\
Total & & & \\
\hline
\end{tabular}

